\title{
Technological Development and Art and Design as a Digital Medium
}

\author{
Huseyin Baran \\ Faculty of Art Design and Architecture, Visual Communication Design, \\ Duzce University, Duzce, Turkey \\ E-mail: huseyinbaran@duzce.edu.tr
}

\begin{abstract}
Technology is the act of creating knowledge in a technical field, creating something new with this knowledge, revealing it with new methods and techniques, and it has progressed with the concept of design. While human beings are in a technological production, they have also designed. Design has altered with the effect of developing technology and has sometimes taken advantage of technological possibilities in different periods of history and has guided it with the vision it has created. Thus, design and technology have always been concepts that affect each other, and the application forms of art and design have changed and developed with technology. In time, the expression of artistic products and computer technologies with hardware and software has created art in digital environment. Just as every technological development is reflected in art and design as new possibilities of use, every new digital work has become a subject that contributes to the development of this new medium from different angles. In this article, the new possibilities brought to the fields of art and design by the digital medium that emerged with the computer technologies that mankind has reached through various periods are discussed with an approach that investigates how traditional methods and techniques are affected by new technologies. Then, the subject has been examined in the context of new perspectives provided by digital medium to the field.
\end{abstract}

Key Words: Technology, art, design, digital design, digital art, virtual reality, art history

DOI: $10.7176 / \mathrm{JSTR} / 6-13-05$

\section{Teknolojik Gelişim ve Sayısal Bir Medyum Olarak Sanat ve Tasarım}

\begin{abstract}
Özet
Teknoloji, teknik bir alanda bilgiyi olușturma, bu bilgiyle yeni bir şeyler var etme, yeni yöntem ve tekniklerle o şeyi ortaya çıkarma fiilidir ve tasarım kavramıyla birlikte ilerlemiștir. İnsanoğlu teknolojik bir üretim içerisindeyken bir taraftan da tasarlamıştır. Tasarım, gelişen teknolojinin etkisiyle başkalaşmış ve tarihin farklı dönemlerinde teknolojik olanaklardan kimi zaman faydalanıp kimi zaman da ortaya çıkardığı vizyonla ona yön vermiștir. Böylelikle tasarım ve teknoloji daima birbirine etki eden kavramlar olmuş, sanat ve tasarımın uygulama biçimleri teknoloji ile birlikte değişmiş ve gelişmiştir. Zamanla sanatsal ürünün, bilgisayar teknolojilerinin donanım ve yazılım olanaklarıyla ifade edilmesi, sayısal ortamda sanatı doğurmuş ve her teknolojik gelişimin sanat ve tasarıma yeni kullanım olanakları olarak yansıması gibi, her yeni sayısal eser de bu yeni mecranın gelişimine farklı açılardan katkıda bulunan birer özne haline gelmiştir. Bu makalede, insanoğlunun çeşitli dönemlerden geçerek ulaştığı bilgisayar teknolojileriyle ortaya çıkan sayısal medyumun, sanat ve tasarım alanlarına getirdiği yeni olanaklar, geleneksel yöntem ve tekniklerin yeni teknolojilerden nasıl etkilendiğini ve sayısala evrildiğini araştıran bir yaklaşımla ele alınmıştır. Ardından konu, sayısal uzamın alana sağladığı yeni bakış açıları bağlamında irdelenmiştir.
\end{abstract}

Anahtar Kelimeler: Teknoloji, sanat, tasarım, sayısal tasarım, dijital sanat, sanal gerçeklik, sanat tarihi 


\section{Giriş}

Teknoloji ve tasarım alanları için bugüne dek yapılan onlarca tanım, bu alanların farklı alt disiplinlere sahip olmaları nedeniyle bir zorunluluğun gereğidir. Zira teknoloji ve tasarım olguları insanoğlu var olduğundan beri onunla birlikte yaşamının bir parçası olmuş ve zamanla gelişerek birbirine etki eden farklı dallara ayrılmıştır. Modern dünyanın sistemli bir biçimde ilerleyen ve her geçen gün ivmelenerek gelişen teknoloji kavramı, bir ürün veya eserin ortaya konmasında izlenen yol ve yöntemlerin belirleyici rol oynadığı Tasarım Süreçlerinin nasıl başladığı sorusunu akla getirmektedir. Nöron adı verilen milyarlarca sinir hücresiyle örülmüş muhteşem hızlarda veri akışı sağlayan bilgi-işlem ağına (Herculano-Houzel, 2009, s. 1) ve aldığ1 yeni bilgileri eski tecrübeleriyle karşılaştırıp bunlardan yepyeni fikirler ortaya çıkarabilme yetisine sahip olan insan, varolduğu günden bu yana karşısına çıkan sorunlara çözümler üretme eğiliminde olmuştur. Yerinden oynatılamayacak ağırlıktaki nesneleri, tasarladığı kaldıraçla hareket ettirmesi, tekerleği yapması veya ateşin kullanımına dair bilgi oluşturması, kulağa basitmiş gibi gelen, fakat aslında bir tasarım sürecinin ortaya konduğu durumları ve ciddi teknolojik gelişmelerin ilk adımlarını işaret etmektedir (bkz. Görüntü 1).

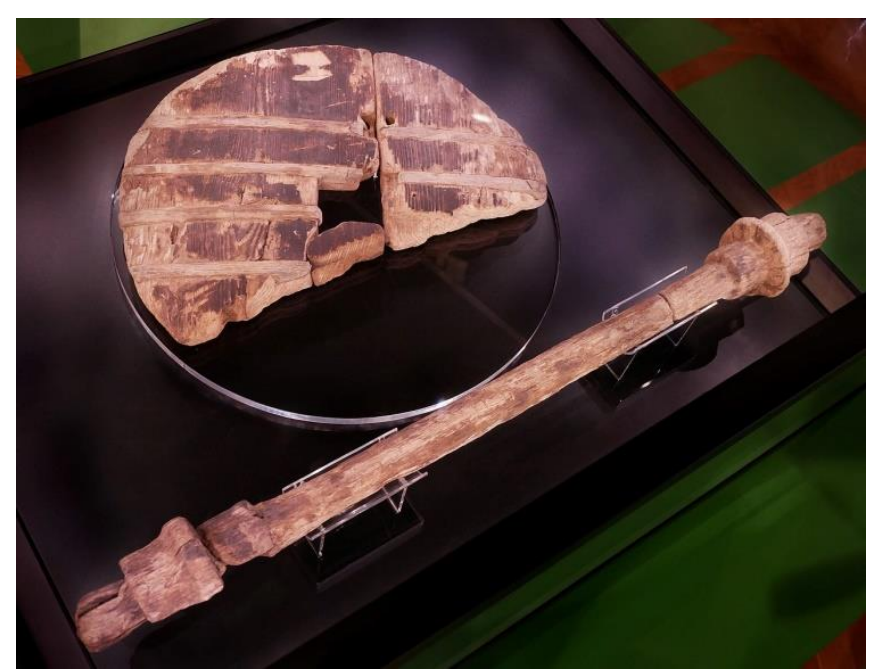

Görüntü 1: Radyokarbon tarihlemesiyle 5.150 yaşında olduğunu ortaya çıkan, Ljubljana Bataklık Çarkı

(https://www.ancient-code.com/wp-content/uploads/2018/05/Oldest-wheel.jpg)

Tarih boyunca insanlık, besin kaynaklarına ulaşmak konusunda av malzemeleri için, dış dünyanın tehlikelerinden korunması gerektiğinde ev yapımı için, yerleşik yaşama geçtiğinde tarım ve hayvancılık malzemeleri için, köyler kurduğunda iş yükünü azaltmak, şehirler kurduğundaysa gündelik yaşamı kolaylaştırıp yaşam alanlarını düzenli hale getirebilmek için tasarım süreçlerini işe koşmuş ve zamanla tutarlı tasarım sistemleri oluşturmuştur. Tasarlama eylemi insanlık geliştikçe, yalnızca bir problem çözme süreci olmaktan çıkıp hem işlevsel olma, hem de içerisinde estetik kaygı barındırma evresine geçmiş ve modern tekniklerle desteklenmiş tasarım bilinci filizlenmeye başlamıştır. Bu bilinçlilik hali zamanla gelişerek farklı dönemlerde farklı anlayışların ortaya çıkmasına yol açmış ve teknolojik gelişimin tasarım ile birbirilerini etkilemelerini sağlamıştır.

Teknolojik, örgütsel ve kültürel değişimlere koşut bir biçimde, araçları ve yöntemleri değişmiş olsa da insanın tasarlama yeteneği sürekliliğini korumuş, tasarım biricik ve değişmez bir insan yetisiyken, uygulanış biçimi olarak tarih boyunca devinim içerisinde var olmuş ve kendisini çeşitli şekillerde göstermiştir (Heskett, 2013). 


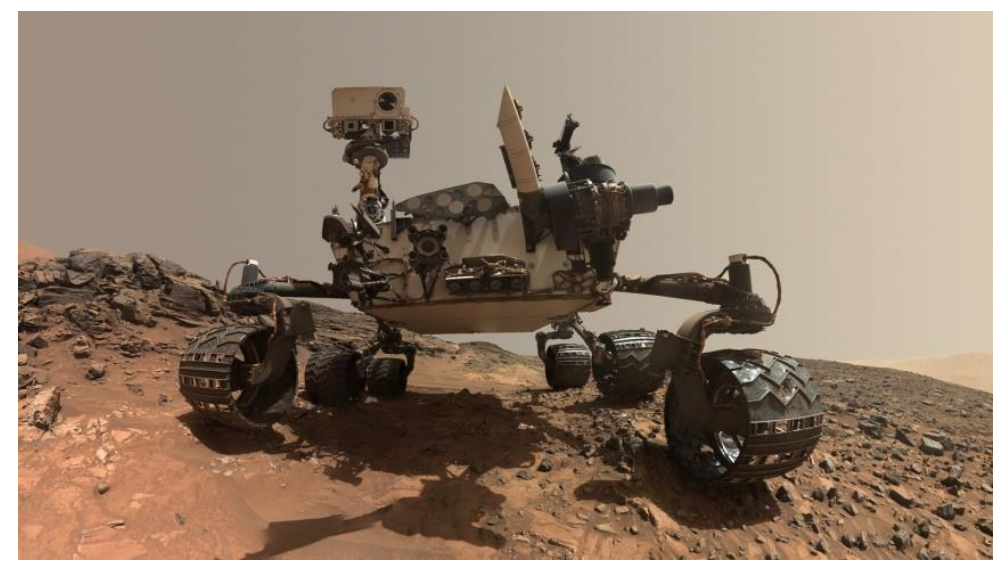

Görüntï 2: Mars'ta Gale kraterinde keşifte bulunan, gezgin robot Curiosity

(https://mars.nasa.gov/system/feature_items/images/6037_msl_banner.jpg)

Amacı; nesnel bilgi ve tekniğin nasıl ortaya çıktığını, yayılışını ve kullanıldığı koşulları incelemek, bu konuda nitelikli, yöntemli bir düşünme biçimi ve bakış açısı oluşturmak olan teknoloji tarihi (Yörükoğulları, 2013, s. 4) insanın bir taş parçasını biçimlendirip onu varolduğundan farklı bir amaçla tekerlek olarak kullanabileceğini akıl etmesi ile başlayarak, aynı bakış açısıyla hazırlanmış tekerleklere sahip bir araç ile Mars’ta hareket etmesine kadar evrilmiştir (bkz. Görüntü 2). Dijital teknolojilerde yaşadığı gelişim ise insanı, avuç içine sığacak büyüklükteki iletişim araçlarıyla Ay tutulmasını çekip yazılımlarla işleyerek, sosyal medyada tüm insanlıkla bir tuş yardımıyla paylaşabileceği günümüz seviyesine ulaştırmıştır.

\section{Sanayi Ürünleri ve Estetik Değerler Bağlamında Gelișimi}

Yunanca'da sanat anlamına gelen "tekhne" ve bilmek anlamina gelen "logos" kelimelerinin birleşiminden oluşan "teknoloji” terimi, adının kaynağından da anlaşılacağı gibi, insanoğlunun ihtiyaçları dahilinde ortaya çıkardığı araç gereçlerin yapımı konusunda bilgi ve yetkinliğe sahip olması anlamını taşır (Vural, 2008, s. 6). Bu anlam insanoğlunun düşünce biçimlerini geliştirip, ürünlerini bilimsel bir temele oturtarak sistemli hale getirmesi ile pekişmiş ve günümüze, teknolojinin zihinlerimizde yarattığı geniş anlamıyla ulaşmıştır.

Günümüz teknolojisi ile geçmişin ilkel olarak adlandırılabilecek araçları arasındaki bağ, bugün görülen ciddi farklılıklara rağmen çok güçlüdür. İnsanın ilk tasarlama eylemleri ile, örneğin bir taşı kırıp keskin olan parçasını seçerek meyveyi kabuklarından ayırması ve içeriğini bu sayede tüketebilmesiyle, bugün kurduğu devasa tesislerde meyvelerin suyunu teknolojik araçlarla çıkararak şişelere doldurması ve içilmek üzere tüketime sunması arasında, izlenen yöntem ve tekniklerin sistematikliği açısından büyük farklılıklar olsa da, ulaşılmak istenen amaç olan meyvenin içeriğini tüketme ortak paydasında ciddi benzerlikler vardır. Onbinlerce yıl süren ve binlerce aşamadan geçen teknolojik ilerlemenin temelinde, keskin yüzeyin bu amaçla kullanılabileceği bilgisinin, bir zamanlar bunu düşünen insan tarafindan araca dönüştürülmesi ve bilginin aktarılarak zamanla evrilmesi yatar. Bu evrim, ürünlerimizin yalnızca işlevsel özelliklerine değil, sanatsal bir kaygı taşıyan estetik özelliklerine de yansımıştır.

Ürün ile tasarımın birlikte var olduğu argümanı, ürün ve sanat arasındaki birliktelik konusunda aynı paralelde gerçekleşmemiştir. Zira her ürün bir tasarlama eylemi içermekte iken, aynı zamanda her ürün sanatsal bir kaygı güdülerek ortaya çıkarılmış değildir. İnsanoğlu ürünler geliştirirken, öncelikle üretime yönelmesine sebep olan temel ihtiyacını karşılayacak çözümlere odaklanmaktadır. Avlanması gerektiğinde bir mızrağa ihtiyacı varsa, bunun için dönemin şartlarını da göz önünde bulundurmak koşulu ile pürüzlerinden arındırılmış bir ağaç dalı, sivriltilmiş bir taş parçası ve bu ikisini birbirine bağlamak için bir miktar urgan, amacına uygun aracı ortaya çıkarması için yeterli malzemelerdir. Bu aracı kendi elleri ile üreten kişinin öncelikli amacı avlanmak, kendisini ve ailesini doyurarak hayatta kalmalarını sağlamaktır. Ürettiği araç amaçlanan doğrultuda sorunsuz bir biçimde kullanılabiliyorsa yeterliğini kanıtlamış demektir.

İnsanın, bir aracı kafasında tasarlayıp elleri ile şekillendirebilme ve üretebilme yeteneği, onu çevresindeki diğer canlılardan ayıran en önemli unsur olmuştur. "İnsanoğlunun elinde uzun zaman geçirerek bıçă̆a dönüşen ilk taş parçasının yanında, bilinen tarihin önemsizliğine” vurgu yapan

37 | P a g e

www.iiste.org 
Engels, insanın elleri ile daha önce eşine rastlanmayan yaratı ürünleri ortaya koymasının önemine değinerek "el artık özgürlüğ̈̈ne kavuşmuştur ve böylece giderek daha çok beceri kazanmıştır; bu becerilerle birlikte giderek artan kıvraklık da kuşaktan kuşağa geçmiştir. Bu açıdan bakıldiğında el, çalışmanın yalnızca bir organı değil, aynı zamanda bir ürünüdür” demiştir. Bu cümleden çıkarılabilecek anlam ise insan elinin ilk teknolojik ürün olduğu düşüncesidir (Uğurlu, 2008, s. 254).

Engels'in deyişiyle ilk teknolojik ürün olan “eller”, insanoğlunun düşünebilme yetisi, kendini ifade etme ihtiyacı, varlığını birşeyler var ederek anlatma çabası ve estetik kaygı güdüsüyle birleştiğinde, Maslow'un ihtiyaçlar hiyerarşisinde en alt basamakta yer alan "karnını doyurup hayatta kalma" hedeflerine ulaştıktan sonra bir kenara çekilmesine engel olmuştur (Kula, 2015, s. 195). Kendisini tasarıları yoluyla ifade eden insanın, mızrağın ucundaki taş parçasını çeşitli sembollerle bezemesi ve ahşap gövde üzerine kendi bireyselliğini tanımlayacak simgeler aktarma yatkınlığı, kaynağını bu yeteneklerden almıştır. Araçların üretilebilir hale gelmesinin ardından, o araçlara insanoğlunun benliğinde var olan, ürüne kendisinden izler taşıyan özel bir anlam yükleme eğilimi ve insanın güzele dair ihtiyacına da cevap olabilecek estetik dokunuşlar yapma aşamasına geçilmiştir. İnsanoğlunun ürünlerini ortaya çıkarırken onlara simgesel bir vizyon eklemesi ve araçlarında yalnızca işlevsel değil aynı zamanda estetik bir kaygı gütmesi, uzun bir süreci içerisinde barındıran tutarlı bir gelişimi ifade eder. Önceleri yalnızca amaca yönelik olan ürünler, daha sonra güzele dair düşünce ve bakış açıları ile yeniden ele alındığında, ortaya çıkan yeni ürün, görünen maddeselliğinden çok daha derin anlamlar taşıyan, manevi değer atfedilmiş bir karakter kazanmıştır (bkz. Görüntü 3).

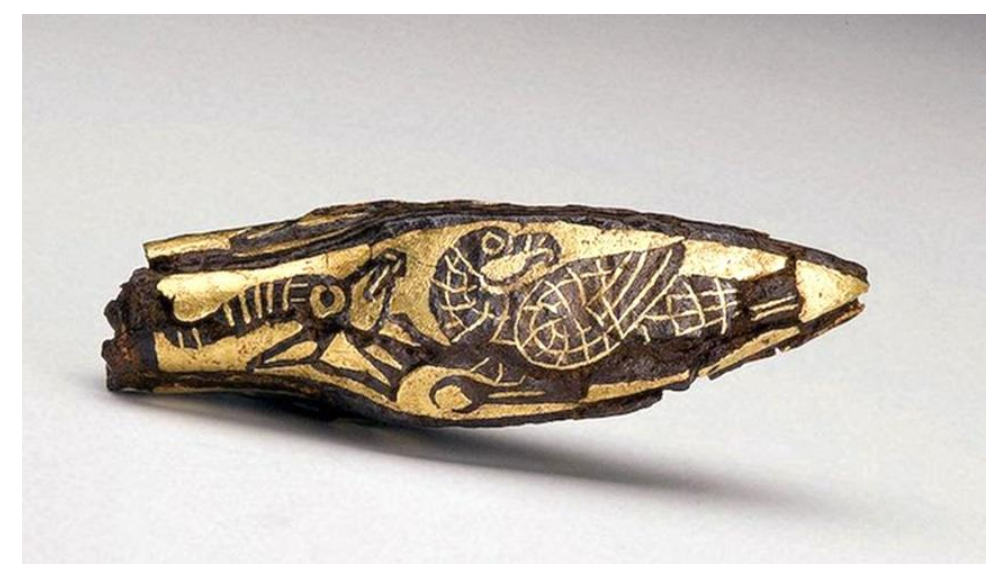

Görüntü 3: Kuş ve Antilop figürlü İskit Türklerinin ok ucu, Arzhan Kurgan1-Tuva M.Ö. 700

(https://s-media-cache-ak0.pinimg.com/originals/96/0e/64/960e6422ed028fac03c79b5ef4666211.jpg)

İlkel devirlerdeki biçimlendirilmiş taş ve kaya parçalarından, mağara yüzeylerindeki ilk görsellerin tasarlanmasında kullanılan gereçlere, Mezopotamya'nın nehir kıyılarında kurulan yerleşik toplulukların araçlarından, yazının ilk formlarına, piramitlerden fresklere, matbaadan Sanayi Devrimine ve günümüz dijital araçlarına kadar, teknolojik gelişim süreklilik göstermiş, sanat ise bu gelişmelerden en fazla etkilenen alan olarak, ortaya çıkarılan ürünlerin bir anlam taşımalarını ve onları sıradan olandan ayıran bir karakter kazanmalarını sağlamıştır. Teknoloji, sanat ve tasarım birlikteliğinin geçmişten günümüze ulaşırken izlediği bu uzun soluklu yolda yaşanılan gelişmelerin bazıları, yaşandığı dönem ve etkilediği kendinden sonraki dönemler itibarı ile ciddi öneme sahiptir. Bu dönemler, günümüz teknolojisine ve bu teknolojinin sanat ve tasarım yaklaşımlarımızı nasıl etkilediğine dair birbirini tamamlayan sistemli bir süreci anlamlandırmaktadır.

Sanayi Devrimi'nin getirdiği vizyonla, dünyanın büyüyen nüfusunun ihtiyaçlarını karşılamaya yönelik üretim makineleri yaygınlaşmış, iş akışı aşamalara bölünmüş, kitlesel üretim için gerekli iş gücüne duyulan ihtiyaçtan işçi sınıfı doğmuştur. Büyük işçi sınıfları iş gücüne katılarak devasa fabrikalarda makineler yardımı ile üretim sürecine dahil olduğunda, sanayide seri üretim dönemi başlamış ve bu üretim süreci bir süre sonra tekdüze ve estetikten yoksun ürünlerin ortaya çıkmasına sebep olmuştur.

Sanat; "Gerçek olanı güzel tasarımlarla yansıtan özel bir toplumsal bilinç ve insan devinimi biçimi" (Ozankaya, 1975, s. 82) veya "Insanla nesnel gerçeklik arasındaki estetik ilişki” (Hançerlioğlu, 1982, s. 364), olarak tanımlanabilir. Tam da bu nitelikleriyle sanat devreye girerek, gelişen teknoloji ve 38 | P a g e 
sanayinin seri ürünlerini nitelikli ürünlere dönüştürecek bir vizyon olarak öne çıkmıştır.

Varlık nedeni hiçbir dönemde bütünüyle aynı kalmayan sanat, toplumlar değişse bile hiç değişmeyen bir gerçeği yansıtma niteliği ile var olmuştur. 20. yüzyıl insanını tarihöncesi mağara resimleri karşısında ya da çok eski ezgileri dinlerken heyecanlandıran şey, sanatın bu niteliğidir (Yılmaz, 2010, s. 337). İnsanoğlunun yaşamı, sanayi çağında üretilen endüstri ürünlerinden bağımsız düşünülemeyeceğinden, endüstri ürünlerinin tekdüzelikten sıyrılarak bir karakter kazanması ve estetik dokunuşlardan sonra tüketicisine ulaşması gerekliliği, sanat ve tasarımın, toplumun yaşam standartlarını yükseltecek bir misyon üstlenmelerini sağlamıştır. Sanayi toplumunun gelişen ve dönüşen yaşamında tasarım ürünleri, müze ve galerilerde sergilenmekle kalmqmış, hayatın içine dahil olarak yaşam alanlarının birer parçası haline gelmişlerdir. Sanatla buluşan tasarımlar sayesinde estetik bir kaygı ile evrilen yaşam alanlarının içerisinde varlığını sürdüren insan, hızla gelişen bu yeni sosyal ve kültürel ortamda kendisine sıradan olanın dışında bir anlam bulabilmiştir.

\section{Teknolojik Etki ve Herkesi İçin Tasarım}

Öncelikle işlevsel ve bununla birlikte estetik ürünler ortaya çıkarma konusunda teknolojinin ve makinenin varlığını olumlayan Bauhaus'ta, sanat ve tasarım, bilim ve teknoloji ile uygulama sahasında bir bütünlük meydana getirmiştir. Bauhaus ekolü, bir tarz veya bir eğitim hareketinden öte, 1850'lerden beri Avrupa'da yürürlükte olan kültürel, ekonomik ve toplumsal bir modernleşme programını ve yeni bir hayatın tasarlanabileceği inancını temsil etmiştir. Bu okulun, kendisinden sonraki teknoloji ve sanat eğitimi üzerinde derin etkileri olmuştur (Özkaplan, 2009, s. 9).

Bauhaus çağdaş uygarlık için gerekli gördüğü endüstriyel gelişim, teknik altyapı ve makineleşmenin yanında, bu gelişmelere parallel olarak sanat ve tasarım ürünlerini toplum için ulaşılabilir kılma misyonunu da üstlenmiştir. Uygulanan eğitim sistemi sayesinde sanatçılar, kitlelerin sorunlarını ele alıp dile getirmenin yanı sıra, bu sorunlara eserleri aracılığıyla çözüm üretmeyi de hedeflemişlerdir. Okulun kurucusu Gropius güzel sanatlar ile tasarım sanatlarının ortak köklerini görerek bu okulda sanat, tasarım ve endüstri arasındaki bağları yeniden kurmayı, bu sayede sanat ile endüstriyi birleştirmeyi amaçlamıştır. De Stijl ve Bauhaus'ta olduğu gibi Kübistler, Fütüristler, Süprematistler, Konstrüktivistler ve Dadaistler çeşitli biçimlerde birbirilerine etki etmiş, daha önce benzeri görülmemiş bir vizyonla sanat ve tasarım faaliyetlerini ortaya koymuş, modern dünyanın endüstrileşen yapısına yalın bir bakış açısıyla katkıda bulunarak, sanat ve tasarımın toplumsal fayda gözetilerek bir araya getirilmesinde aracı olmuşlardır. Endüstri ve tekniğin hızla yenilendiği "geleceğin dünyası" vizyonuyla ürettikleri tasarılar, yalnızca nesnelerin yeni uyarlanma biçimlerini ortaya koymakla kalmamış, bu sayede sanat ve tasarım ürünlerinin yer aldığı ve insanın yaşamını sürdürdüğü ortamı da şekillendirmişlerdir. Sanat ve tasarım ürünlerini, sayılı gözlerin görebildiği hapisanelerinden çıkarıp seri üretim nesnelerine uyarlayarak, herhangi bir mekanın ürünle birlikte sergilendiği bir sanat mekanına dönüşmesini sağlamışlardır. Günümüzün gelişmiş dijital sanat teknikleri ile oluşturulan görsel tasarım ürünlerini, hava alanları, istasyonlar, super market zincirleri, alışveriş merkezleri, yüksek binalar ve bu binalara entegere edilmiş devasa ekranlara sahip şehir merkezleri aracılığyla hedef kitlesine ulaştıran bilgi, 20. yüzyılın ilk çeyreğinde ortaya konan yenilikçi ve modern bakış açılarına sahip bu akımlar ve sanatçıların vizyonu ile temellenmiştir. Tarihsel süreç içerisinde sanat ve tasarım farklı koşullardan değişkenden etkilenmiş ve kendisini ifade etmek için gelişen ve değişen tekniklerle yeni yollar bularak toplumun yapısına ve insanlığın kültürel mirasına yön vermiştir. Modernizm'in çıkış noktası olan "bireyin yaşamını devam ettirebilmesi için kendi özelliklerinin yansıtıldı̆̆ teknoloji ve endüstri ürünlerine karşı bir sav üretmesi ya da bunlarla beraber hareket etmesi gerekir" sözü, sanat ve tasarımın endüstriyel dönemle birlikte gelişen teknolojik olanaklardan nasıl etkilendiğine dair güzel bir örnektir.

İcat edildiği tarihten itabaren hem bilim hem de sanayi için vazgeçilmez bir araç olan fotoğraf, kitle iletişimin, sinemanın, televizyonun ve video kasetlerin temelini oluşturmuş, binlerce gazete, dergi, basılı yayınlar ve internet aracılığıyla yaşantımızın içerisinde sürekli biçimde yer almaya devam etmiştir (Freund, 2016).

Bilgisayar, donanım ve yazılım teknolojilerindeki gelişimin yanı sıra dijital görüntüleme teknolojilerindeki gelişmelerin yolu bir noktada fotoğraf teknolojileri ile kesişerek görsel tasarım konusunda yepyeni fikirlerin ve bakış açılarının oluşmasını sağlamıştır. Teknolojideki gelişmeler 20. yüzyıl sanat anlayışına yön vermiş, tuvalin yerini monitörler, enstalasyonlar, happeningler, performanslar, video sanatı, vücut sanatı ve fluxus gibi sanat türleri almıştır (Kozlu, 2009, s. 10) (bkz. Görüntü 4).

39 | P a g e 


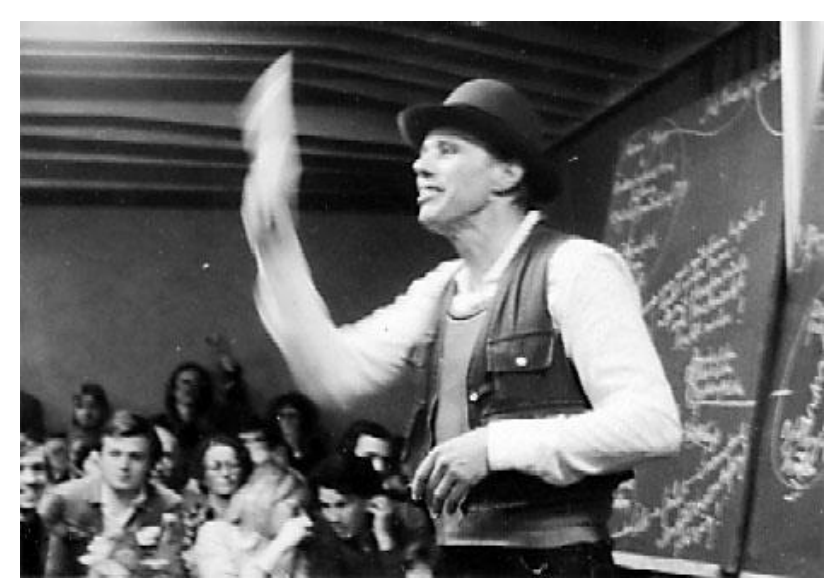

Görüntü 4: Joseph Beuys performans1, 1978

(https://upload.wikimedia.org/wikipedia/commons/9/9b/BeuysAchberg78.jpg)

İnsanoğlu, kendisine ayırdığı zamanın giderek azaldığı bu yüzyılın durmak bilmeyen devinimi içerisinde, yaşamın hızlı doğasına ayak uydurmuş, topluma ulaşabilmek için ürünü yeniden ele alarak rafine tasarımlarla öne çıkarmıştır. 21. Yüzyılda insan, masaüstü bilgisayarlardan dizüstü bilgisayarlara, profesyonel dijital fotoğraf makinelerinden, her biri kendine has kamera, işletim sistemi ve uygulama yazılımlarına sahip mobil telefonlara kadar tüm iletişim araçlarını etkin bir biçimde kullanmaya başlamıştır. Bu iletişim araçları üzerinden dünya ile paylaştığı ve dünyanın kendisi ile paylaştığ 1 sınırsız dijital veri, insanı bu veriler içerisinde sanatsal bir vizyonla üretilmiş olanı aramaya itmiştir. Bu estetik arayışı, tasarım ürünü, sanat yapıtı ve izleyici arasındaki bağı dönüştürerek yeni bir bilincin sinyallerini vermiştir.

Dijital dünyanın yeni olanakları ve tasarım kültürüne katkıları düşünüldüğünde, her bir sanat eserinin eylem aşamasına geçmeden önce, bir zamanlar fikir düzeyinede var olduğu gerçeğiden hareketle, teknolojinin bu fikirlerin nasıl sanat ve tasarım ürünleri olarak hayata geçirileceğini belirleyen önemli bir etken olduğu sonucuna ulaşılmaktadır (Erbay, 2014, s.189).

\section{Sayısal Medyumda Sanat ve Tasarım}

Sanatın teknoloji ile bağına etki eden bilgisayar teknolojilerinin gelişim serüveni, görsel tasarımın sayısal boyutunun daha iyi anlaşılmasını sağlamaktadır. Gelişen bilgisayar teknolojileri sanat alanına etki eden ilk çalışmalarını 1960’lı yıllarda ortaya çıkarmaya başlamış, Almanya bilgisayar teknolojileriyle bağlantılı bir çok sanat eserinin yer aldığı sergilere ev sahipliği yapmış ve bilgisayar sanatı sergileri açılmaya başlamıştır. Sayısal ortamlar, bilgisayar teknolojilerinin emekleme dönemi sayılabilecek o yıllarda sanatın içerisinde varlık göstererek sanatçıların tamamen farklı bir medyumun olanaklarıyla kendilerini ifade etmelerini sağlamıştır.

Sonraları çeşitli uygulama yazılımlarının aynı anda çalıştırılabilmesine olanak veren sistem yazılımları, görsel tasarımcıların birden fazla yazılımı senkronize bir biçimde kullanabilmelerini sağlamış, bu sayede iş akışları değişim geçirmiştir. Monitör ve görüntü işleme teknolojilerinin gelişimiyle tasarımcılar, ürettikleri çalışmaları, kitlelere milyonlarca pikselin farklı renklere bürünen varyasyonları şeklinde ulaştırma imkanı bulmuşlardır. İnternetin getirdiği iletişim gücünün katkıları ile bir yandan bu yazılımları kullanarak sanat ve tasarıma yeni bakış açıları getirmiş, ayrıca çalışmalarını hedef kitleleri ile paylaşma konusunda yeni platformların iletişim hızını deneyimleyebilmişlerdir.

Bruce Wands, Dijital Çağın Sanatı isimli kitabında sanatçı ve tasarımcının bu konudaki duruşunu şu cümlelerle aktarmıştır; "Dijital sanatlar; resim, fotoğraf ya da video karesi şeklinde ortaya çıkabilecekleri gibi, ya sanatçının ya da ticari yazılım eseri olan bir bilgisayar programının ürettiği görselleş̧tirmeler şeklinde de görülebilir" (Birol, Gürbüz, 2015).

Günümüz dünyasında sanatçı ve tasarımcıların eserlerini sergilemeleri konusunda teknolojinin sunduğu olanaklar oldukça gelişmiştir. Bilgisayar teknolojilerine paralel bir biçimde gelişen görüntüleme teknolojileri sayesinde bugün insanoğlunun ulaştığı her mekanın birebir görüntüsü neredeyse eş zamanlı olarak diğer insanlarla paylaşılabilmektedir. De Stijl, Bauhaus ve benzeri modernist sanat

40 | P a g e

www.iiste.org 
yaklaşımlarının 20. yüzyılın ilk çeyreğinde hayalini kurdukları "Sanatın topluma ve sosyal hayata ulaştırılarak yaşamın bir parçası haline getirilmesi" ideali, bugün avuçlarımıza sığan ve internet sayesinde bizi dünyanın diğer ucundaki bir tasarım sergisine taşıyabilen iletişim araçlarıyla, milenyum çăgında vücut bulmuş gibidir. Televizyonlardan bilgisayar monitörlerine, elektronik reklam panolarından, cep telefonlarına kadar, internet ağı sayesinde her bilgiye anında ulaşmamızı sağlayan teknolojilerin gelişimi ve sanatçının yeni tuvali haline gelmesi, görsel tasarım ve dijital sanatlar için, yeni bir sunum mecrası olması anlamında önemli bir gelişimi temsil etmiş̧ir.

$\mathrm{Bu}$ teknolojik gelişmelerin en etkililerinden biri olan dokunmatik ekran teknolojileri, sanatçılar için önemli yenilikleri beraberinde getirmiştir. Dokunmatik özelliğe sahip ekranlar, herhangi bir ekran üzerine yerleştirilmiş, basınca duyarlı ekran yüzeyinden parmak veya ekran kalemi aracilığıyla giriş alabilen teknolojilerdir (Çakır, 2011, s. 1). Tasarımı oluşturmada alışılagelmiş dijital teknolojik olanaklardan olan klavye veya fare donanımlarını kullanma gerekliliği, basınca duyarlı yeni ekran teknolojileri sayesinde çeşitlenmiş, sanatçı, ellerini veya bu iş için özel olarak üretilmiş basınç hassasiyetine sahip dijital kalemleri kullanarak, ürettiği esere doğrudan temas edebilmiştir. Kireç taşı, kalem, modelaj aletleri, kağıt veya tuval yüzeyini kullanırken sanatçıya yol gösteren dokunma duyusu, dijital yüzeyde de devreye girmiş ve sanatçının çizgi karakteristiğinin dijital yüzeye doğrudan aktarılmasını sağlamıştır (bkz. Görüntü 5).

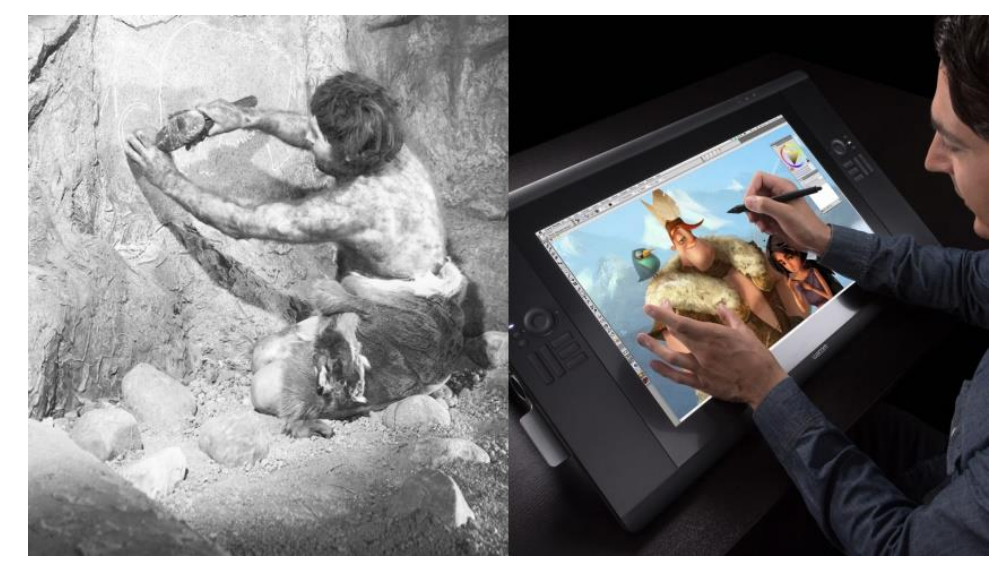

Görüntü 5: İlkel araçlarla mağara duvarına çizim yapan ilk insanlardan, basınca duyarlı ekran üzerine dijital kalemle çizim yapan modern insana, görsel aktarımın evrimi.

Tekonoloji çağının hızla gelişen ve evrilen dünyasında sanatçı ve tasarımcının vazgeçilmez üretim araçları olarak görülen ve onlara yeni ifade biçimleri sunan bilgisayar donanımları, kullanıcılarını dijital sanatın merkezine taşıarak, onların hayal dünyasından sanal dünyalara uzanan eserler üretebilmesine olanak vermiştir. İnsan zihni ve özellikle de bir tasarımcının hayal dünyası sürekli olarak daha önce var olmayan bir şey yaratmaya çalışır (Batiha, 2006, s. 1). Bilgisayar teknolojilerinin dijital sanatı var etmesi ve sağladığı olanaklar sayesinde bugün, sanal gerçeklik donanımlarını giyen tasarımcılar, bilgisayar ortamında modelledikleri bir eseri kendi mekanı içerisinde, üstelik eserin çevresinde dolaşarak gözlemleyip, birlikte tasarlayabilecekleri bir sayısal medyuma kavuşmuştur (bkz. Görüntü 6). 


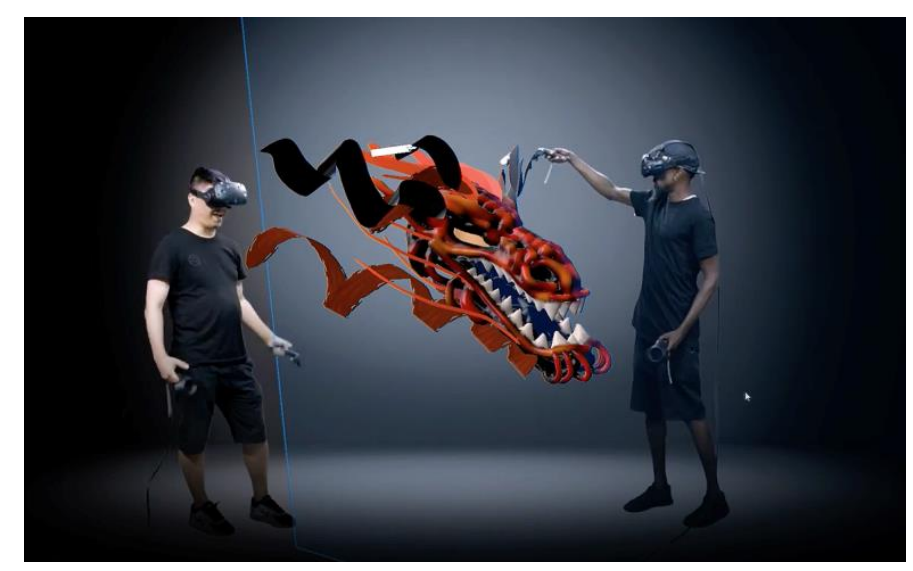

Görüntü 6: Sanal gerçeklik donanımlarıyla, aynız yazılım arayüzünde modelleme yapan tasarımcılar.

(https://3apq3bncl820596k2d1ydn1-wpengine.netdna-ssl.com/wp-content/uploads/2017/09/masterpiece-vr-sculpt.png)

Günümüzde dijital teknolojiler yoluyla oluşturulan sanal gerçeklik uzamları, yüzeyler üzerindeki görüntülerden ibaret olmanın ötesine geçerek, hareketli, sesli veya holografik yapılarıyla, birden fazla duyuya hitap etmekte ve bu duyular üzerindeki etkileri aracıllğıyla algımızda yarattıkları gerçeklik hissini arttırmaktadırlar. Bu bağlamda sanal gerçekliği işlevsellik bakımından ele aldığımızda, gerçeğe olabildiğince yakın bir dünya yaratmak için bilgisayar grafiklerinin kullanıldığı çeşitli simülasyonlar olarak açıklayabiliriz (Kayabaşı, 2005, s.157).

Bir dijital tasarımın içerisinde onu tüm yönleriyle inceleyip deneyimlememize imkan veren bu yakınlaşma, bir zamanların yalnızca 2 boyutlu ekranları üzerinde var olan dijital görseller dünyasına üç boyutlu sanal gerçeklik arayüzü ile $\mathrm{Z}$ eksenini de dahil ederek, sanal medyumun üçüncü boyut devrimini gerçekleştirmiştir (bkz. Görüntü 7).

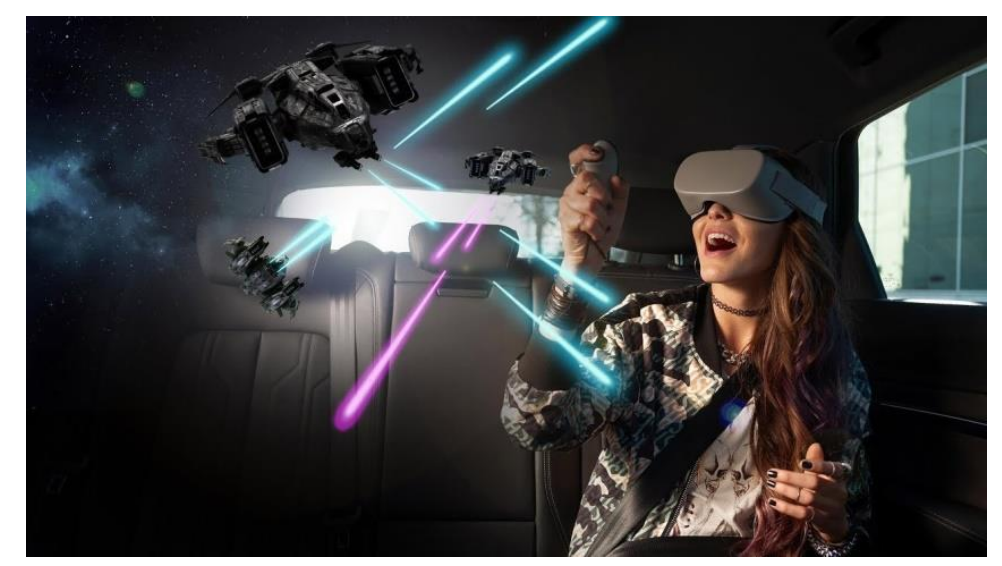

Görüntü 7: Gelişen donanım teknolojileriyle deneyimin gerçekçiliğini her geçen gün artıran sanal gerçeklik uzamı.

(https://i.ytimg.com/vi/3eBVc2zuQ8Y/maxresdefault.jpg)

Bilgisayar ve donanım teknolojilerindeki gelişmelerin sanatsal bir yansıması olan dijital sanat, fizik ve matematik gibi bilimlere olan yakınlı̆̆ından dolayı geleneksel anlamıyla sanat, sanatçı, sanat yapıtı ve izleyici kavramlarını da değiştirmektedir. Bilgisayar teknolojisi, sadece baskı, resim, fotoğraf, video, müzik ve heykel gibi sanatın geleneksel formlarını dönüştürmekle kalmamış, internet sanatı, yazılım sanatı, piksel sanatı, dijital sergilemeler ve sanal gerçeklik gibi tüm yeni formların da sanatsal çalışmalar olarak kabul edilmelerini sağlamıştır (Sağlamtimur, 2010, s. 214) (bkz. Görüntü 8). 


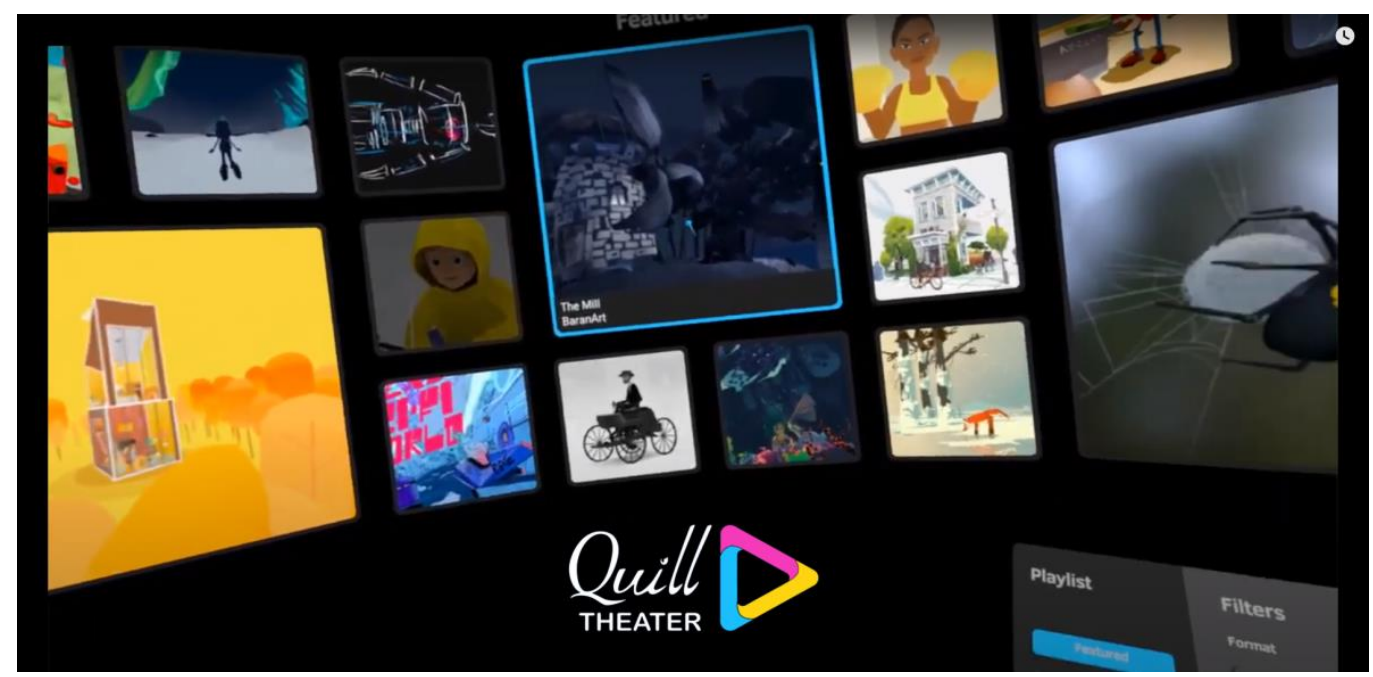

Görüntü 8: Tasarımcıların Quill Sanal Gerçeklik yazılımında oluşturdukları mekan ve karakter temelli animasyonların, online deneyimlenebildiği Oculus Quill Theatre platformu.

Bugün bir tasarımcı, imgeyi düşünsel anlamda ortaya çıkardıktan ve kağıda döktükten sonra dijital ortama aktarıp görsel tasarım yazılımları ile geliştirebilir. Ardından çalışmasını farklı açılardan da izlenebilir kılmak için onu üç boyutlu uygulama yazılımları ile modelleyerek sanal gerçeklik teknolojileri sayesinde, deneyimleyebileceği poligonal yapılara, karakterlere ve mekanlara dönüştürebilir. Böylece sanatçının imgesel dünyasında oluşup teknolojinin sayısal dünyasına aktarılan eser, kağıt yüzeyindeki durağan görsellikten, sanal medyumda hareketli bir biçimde deneyimlenebildiğ $i$ ses ve dokunma duyularına da hitap eden 3 boyutlu uzama aktarılmış olur. Bu uzam, 21. yüzyıl teknolojilerinin sanatçı ve tasarımcılara kapısını araladığı, yepyeni bir uygulama ve sunum evreni alternatifidir.

\section{Sonuç}

Dünyanın diğer ucundaki bir görsel tasarım sergisini, üç boyutlu gözlüklerimizi takıp, sanal sergi salonu içerisindeki eserleri tek tek dolaşarak gezebildiğimiz günümüz dünyasına kıyasla, dijital sanat ilk yıllarında çoğunlukla fuar, konferans ve sergilerde vizyoner sanatçılar tarafindan yapılmış deneysel çalışmalardan ibaretti. Elektriğin sağladığı olanaklardan elektroniğe, bu ilerlemelerden bilgisayar, monitor ve diğer donanım araçlarına, fotoğraf ve sinema sanatındaki gelişmelerden görüntü işlemeye ve tüm bu teknolojilerin sanat ile buluşmasıyla sayısal olanaklara ulaşılan 21. yüzyılda, geleneksel sanat ve tasarım araçları olan kağıt, kalem, fırça, tuval, airbrush, pistole gibi bir çok gereç, bilgisayar ortamında simule edilerek kullanıcısının hizmetine sunulmuştur. Tüm bu olanakların biraraya gelmesini ve tasarımcının mutfağını oluşturmasını sağlayan bilgisayar alanındaki gelişmeler, bulunduğu dönemin sanatsal vizyonuna etki etmiş, kendisinden sonra gelecek teknolojik altyapının da temelini oluşturmuştur. Her dönemde bulunduğu çağı sıradışı bir perspektifle yansitma misyonunu üstlenen sanatç1, günümüzde de eserlerini oluştururken dönemin ona sunduğu yeni enstrümanları kullanarak, teknolojinin ve sayısal dünyanın etkilerini taşıyan ve aynı zamanda onlara etki eden eserler üretmektedir. Bugün dijital sanat ve sanatçı arasındaki ilişkiler, etkileşim boyutu ile ele alındığında, sanat ve tasarıma yeni bakış açıları kazandıran bir yapı gözler önüne serilmektedir. Sanatçı ve tasarımcılar teknolojik olanakları kullanarak, eserlerine yeni anlamlar kazandırmakta, teknoloji çağını sorgulamakta ve bunu yaparken yeni sanat ve tasarım anlayışlarını sayısal dünyanın araçlarını kullanarak geliştirmektedirler. Bu gelişim, bir önceki yeniliğin sanat ve tasarım kültürüne, üretilen eserler aracılığıyla aktarılması ve bu sayede bir sonraki gelişim adımına zemin hazırlayarak onun kullanım olanaklarına dair öngörüyü oluşturulması biçiminde birbirine eklenerek devam etmekte ve geleceğin sanatsal yaklaşımlarını ortaya çıkarmaktadır. İnsanlığın yalnızca teknolojik değil, aynı zamanda bilimsel, edebi, felsefi ve diğer müsbet alanlardaki gelişiminin, sanat ve tasarımın esnek yorumlama gücüyle birleşmesi; yeni sanatsal yaklaşımların, yeni tasarım uygulamalarının, yeni iletişim kanalları ve sayısal uzamların, gelişip evrilen sanat tasarım kültürüyle gelecekteki etkileşimleri sayesinde anlam bulacaktır.

43 | P a g e

www.iiste.org 


\section{Kaynakça}

Batiha, K., AL SALIMEH, S., Besoul, K. (2006, Temmuz-Aralı). Dijital Art And Design. Leonardo Journal of Sciences, 1.

Birol, A., Gürbüz, Y. (2015, Aralık). Dijital Teknolojilerin Resim Sanatına Yansımaları. Türkiye'de İnternet Konferans1,

Çakır, A., Akbulut, F., Altıntaş, V. (2011). Dokunmatik Ekran. Süleyman Demirel Üniversitesi, 1.

Erbay, M. (2014, Şubat). Kültür ve Toplum Üzerinden Sanat ve Bilim Arasındaki İlişki. Art-Sanat Dergisi, 189.

Freund, G. (2016, Mayıs). Fotoğraf ve Toplum. İstanbul: Sel Yayıncılık

Hançerlioğlu, O. (1982). Felsefe Sözlüğü, İstanbul: Remzi Kitabevi

Herculano-Houzel, S. (2009, Kasım). The Human Brain In Numbers: A Linearly Scaled-up Primate Brain. Frontiers InHuman Neuroscience, 1.

Heskett, J. (2013, Ağustos). Tasarım, Ankara: Kültür Kitaplığ

Kayabaşı, Y. (2005, Temmuz). Sanal Gerçeklik ve Eğitim Amaçlı Kullanılması. The Turkish Online Journal of Educational Technology, 157.

Kozlu, D. (2009, Mart). Teknolojik Gelişmelerin Toplum ve Sanata Yansımaları. Süleyman Demirel Üniversitesi, Güzel Sanatlar Hakemli Dergisi, 7.

Kula, S., Çakar, B. (2015). Maslow İhtiyaçlar Hiyerarşisi Bağlamında Toplumda Bireylerin Güvenlik Algısı ve Yaşam Doyumu Arasındaki İlişki. Bartın Üniversitesi İ.İ.B.F. Dergisi, 195.

Ozankaya, Ö. (1975). Toplumbilim Terimleri Sözlüğü, Ankara: Türk Dil Kurumu Yayınları

Sağlamtimur, Z.Ö. (2010, Mart). Dijital Sanat. Anadolu Üniversitesi Sosyal Bilimler Dergisi, 214.

Uğurlu, H. (2008, Şubat). Teknoloji Sanat İlişkisi: Günümüzde Teknolojik Sanatların Amacı. Uşak Üniversitesi Sosyal Bilimler Dergisi, 254., 255., 258.

Vural, B., Sabuncuoğlu A. (2008, Mart). Bilgi İletişim Teknolojileri ve Ütopyan Bakış Açısı. Selçuk İletişim, 6.

Yılmaz, E. (2010, Yaz). Sanayi Toplumunda Sanatın İşlevselliği. Bartın Üniversitesi Elektronik Sosyal Bilimler Dergisi, 337, 346.

Yörükoğulları, E., Orhun, Ö. Topdemir, H.G., İhsanoğlu E. (2013). Bilim ve Teknoloji Tarihi. Eskişehir: Anadolu Üniversitesi 